of the German dealers in wild beasts. Many German travellers originally started from here on their tours, such as Florian, Werner, Cohn, Dr. Schweinfurth, Heuglin. Dr. Mook and Baron Holzhausen intend to move in a south-easterly direction towards the Rahat and Diuder.

THE German Government has supported African research with the sums of 100,000 marks $(5,000 l$.) during 1878 , and 70,000 marks $(3,500 l$.) during 1879 . For the present year it is proposed to devote another sum of 7o,000 marks to this purpose, besides a sum of 5,000 marks $(250 l$.) for the furtherance of independent private research in the Dark Continent.

THE Paris Municipal Council has held a secret sitting to deliberate upon the organisation of a great banquet to Prof. Nordenskjöld. It has been decided that a gold medal be presented to the explorer in the Salle des Etats.

THE municipal authorities of Gossensass, on the Brenner Railway, have re-christened the Huinerspiel peak, famous for the magnificent view which is obtained from its summit, and which lies within their district. The peak will henceforth be called Amthorpeak, in honour of Dr. E. Amthor, of Gera, an eminent "Alpine" writer.

\section{ON THE INFLUENCE OF ELECTRIC LIGHT UPON VEGETATION AND ON CERTAIN PHYSICAL PRINCIPLES INVOLVED}

THE vast development of vegetation proves that dissociation is accomplished freely within the leaf-cells of plants, in which both water and carbonic acid are broken up in order that chlorophyll, starch, and cellulose may be formed. It is well known that this reaction depends upon solar radiation; but the question may fairly be asked whether it is confined to that agency, or whether other sources of light and heat, which, in common with the sun, exceed the temperature of dissociation, may not be called into requisition, in order to continue the action of growth, when that great luminary has set or is hidden behind clouds?

About two years ago I mentioned to Sir Joseph Hooker, then President of the Royal Society, that I thought the electric arc might be found sufficiently powerful to promote vegetation and that I should be willing to undertake some experiments on the subject if he could give me any hope of confirmative results. Sir Joseph Hooker gave me sufficient encouragement to induce me to follow up the subject, and I have since that time gradually matured a plan for conducting the experiment.

The apparatus which has been put up at Sherwood consistsI. Of a vertical Siemens dynamo-machine, weighing 50 kilos, with a wire resistance of 0.717 unit on the electro-magnets This machine makes I, 000 revolutions a minute, it takes 2 horsepower to drive it, and develops a current of 25 to 27 webers of an intensity of 70 volts. 2. A regulator or lamp constructed for continuous currents, with two carbon electrodes of 12 millims. and to millims, diameter respectively. The light produced is equal to 1,400 candles measured photometrically. 3. A motor, which at present is a 3 horse-power Otto gas engine, but which it is intended to supersede by a turbine to be worked by a natural supply of water, at a distance of about half a mile from the house.

My object in making these experiments was to ascertain whether electric light exercised any decided effect upon the growth of plants. For this purpose I placed the regulator in a lamp with a metallic reflector, in the open air, about two metres above the glass of a sunk melon house. A considerable number of pots were provided, sown and planted with quick-growing seeds and plants, such as mustard, carrots, swedes, beans, cucumbers, and melons. The plants could then be brought at suitable intervals under the influence of daylight and electric light, without moving them, both falling upon them approximately at the same angle. The pots were divided into four groups.

1. One pot of each group was kept entirely in the dark.

2. One was exposed to the influence of the electric light only.

3. One was exposed to the influence of daylight only.

4. One was exposed successively to both day and electric light.

The electric light was supplied for six hours, from 5 to II

I Abstract of a paper read at the Royal Society on March 4, by C. William Siemens, D.C.L., F.R.S. each evening, all the plants being left in darkness during the remainder of the night.

In all cases the differences of effect were' unmistakable. The plants kept in the dark were pale yellow, thin in the stalk, and soon died. Those exposed to electric light only showed a lightgreen Ieaf, and had sufficient vigour to survive. Those exposed to daylight only were of a darker green and greater vigour. Those exposed to both sources of light showed a decided superiority in vigour over all the others, and the green of the leaf was of a dark rich hue.

It must be remembered that, in this contest of electric against solar light, the time of exposure was in favour of the latter in the proportion of nearly two to one, but all allowance made, daylight appeared to be about twice as effective as electric light. It was evident, however, that the electric light was not well placed for giving out its power advantageously. The nights being cold, and the plants under experiment for the most part of a character to require a hot moist atmosphere, the glass was covered very thickly with moisture, which greatly obstructed the action of the light, besides which, the electric light had to pass through the glass of its own lamp. ${ }^{x}$ Notwithstanding these drawbacks, electric light was clearly sufficiently powerful to form chlorophyll and its derivatives in the plants.

These preliminary trials go to prove that electric light can be utilised in aid of solar light by placing it over greenhouses, but the loss of effect in such cases must be considerable. I, therefore, directed my observations, in the next place, to the effect of electric light upon plants, when both were placed in the same apartment. The plants under experiment were divided into three groups; one group was exposed to daylight alone, a second similar group was exposed to electric light during eleven hours of the night, and were kept in the dark chamber during the day time, and the third similar group was exposed to eleven hours' day and eleven hours' electric light. These experiments were continued during four days and nights consecutively, and the results observed are of a very striking and decisive character, as regards the behaviour of such quick-growing plants as mustard, carrots, \&c. The plants that had been exposed to daylight alone (comprising a fair proportion of sunlight) presented their usually healthy green appearance; those exposed to electric light alone were, in most instances, of a somewhat lighter, but, in one instance, of a somewhat darker hue than those exposed to day. light; and all the plants that had the double benefit of day and electric light far surpassed the others in darkness of green and vigorous appearance generally. A pot of tulip buds was placed in this electric stove, and the flowers were observed to ofen completely after two hours' exposure.

Although the access of stove heat was virtually stopped, the temperature of the house was maintained throughout the night at $72^{\circ} \mathrm{F}$., proving that the electric lamp furnished not only a supply of effective light, bnt of stove heat also. No hurtful effect was, moreover, observed on the plants from the want of ventilation, and it would appear probable that the supply of pure carbonic acid resulting from the complete combustion of the carbonic electrodes at high temperature, and under the influence of an excess of oxygen, sufficed to sustain their vital functions. If the nitrogenous compounds which Prof. Dewar has shown to be developed in the electric arc were produced in Jarge quantities, injurious effects upon the plants must undoubtedly ensue, but it can be shown that in a well-conditioned electric lamp, with a free circulation of air round the carbon electrodes, the amount of these products is exceedingly small, and of a different nature than is produced in a confined space.

These experiments are not only instructive in proving the sufficiency of electric light alone to promote vegetation, but they also go to prove the important fact that diurnal repose is not necessary for the life of plants, although the duration of the experiments is too limited perhaps to furnish that proof in an absolute manner. It may, however, be argued from analogy, that such repose is not necessary, seeing that crops grow and ripen in a wonderfully short space of time in the northern regions of Sweden and Norway, and Finland, where the summer does not exceed two months, during which period the sun scarcely sets.

The next step in the course of these experiments was to remove the electric lamp into a palm house, constructed of framed glass, which was 28 feet 3 in. long, 44 feet 6 in. wide, and averaging

1 Prof. Stokes has shown, in 1857 , that the electric arc is particularly rich in highly refrangible invisible rays, a circumstance which seems to point to a great loss on passing those rays through glass. 
14 feet 6 in. $(8.62 \mathrm{~m}, \times 14.42 \mathrm{~m}, \times 442)$ in height. In the centre of this house a banana palm and a few other small palmtrees are planted, the sides of the house all round being occupied with a considerable variety of flowering plants. The electric light was fixed as high as practicable at the south corner of the house, in order that its rays might fall upon the plants from a direction and at an angle coincident with those of the sun during the middle of the day. The temperature of the house was maintained at $65^{\circ} \mathrm{F}$, and the electric lamp was kept alight from 5 P.M. to 6 A.M., for one week, from February 18 to February 24, excepting Sunday night. The time was hardly sufficient to produce very striking effects, but all the plants continued to present a healthy appearance. Of three Alicante vines, the one nearest the electric light made most progress, and the same could be said of the nectarines and roses. It was observed that other plants, such as geraniums, continued to exhibit a vigorous appearance, notwithstanding the heat of the place. This experiment is of importance in showing that the electric light, if put into conservatories or greenhouses, does not injure the plants, but rather improves their appearance and growth. The leaves assume a darker and more vigorous appearance, and it seems that the colouring of the flowers becomes more vivid, but a further period of time is necessary to establish this observation absolutely.

I decided to try the effect of electric light as a means of pro. moting growth in the open air and under glass at the same time.

The regulator was put back into its first position, 2 metres above the ground, with a sunken melon house on one side, and a sunken house containing roses, lilies, strawberries, and a variety of other plants on the other. The space of ground between these, about I metre broad and 7 metres long, was covered with boxes sown with early vegetables, including mustard, peas, beans, and potatoes, and in order to prevent cold winds from injuring the plants, low protecting walls were put up across the openings of the passage between the two houses.

Some weeks must elapse before any absolute results can be given, but growth is evidently promoted under all these various circumstances. In order to test this clearly, a portion of the plants both under glass and in the open air are shaded from the electric light without removing them from their position of equal temperature and exposed to solar light during daytime. The effect upon the flowering plants is very striking, electric light being apparently more efficacious to bring them on than daylight. Although the amount of heat given off from the electric arc is not great compared with a gas flame (giving off its products of combustion), yet the rays of intense heat of the arc counteract that loss of heat by radiation from the leaves into space, which during a clear night causes hoar frost. For this reason I expect that electric light may be usefully employed in front of fruit walls, in orchards, and in kitchen gardens, to save the fruit-bud at the time of setting; and in this application electric light will probably be found a useful agent not only to promote rapid growth, but to insure a better yield of fruit.

The experiments seem to lead to the following conclusions :-

I. That electric light is efficacious in producing chlorophyll in the leaves of plants, and in promoting growth.

2. That an electric centre of light, equal to I, 400 candles, placed at a distance of 2 metres from growing plants, appeared to be equal in effect to average daylight at this season of the year, but that more economical effects can be attained by more powerful light centres.

3. That the carbonic acid and nitrogenous compounds generated in diminutive quantities in the electric arc, produce no sensible deleterious effects upon plants inclosed in the same space.

4. That plants do not appear to require a period of rest during the twenty-four hours of the day, but make increased and vigorous progress if subjected during daytime to sunlight and during the night to electric light.

5. That the radiation of heat from powerful electric arcs can be made available to counteract the effect of night frost, and is likely to promote the setting and ripening of fruit in the oren air.

6. That while under the influence of electric light plants can sustain increased stove heat without collapsing, a circumstance favourable to forcing by electric light.

7. -That the expense of electro-horticulture depends mainly upon the cost of mechanical energy, and is very moderate where natural forces of such energy, such as waterfalls, can be made available.

Since writing the above my attention has been drawn to an article in NATURE, vol. xxi. p. $3 \mathbf{I} \mathbf{I}$, giving interesting observations by Dr. Schübeler, of Christiania, on "The Effect of Uninterrupted Sunlight on Plants in the Arctic Regions." These observations fully confirm the conclusion indicated by my experiments with electric light. Not only are plants able to grow continuously, according to Dr. Schübeler, but when under the influence of continuous light, they develop more brilliant flowers and larger and more aromatic fruit than under the alternating influence of light and darkness, whereas the formation of sugar appears to be dependent chiefly upon temperature.

It would follow from these observations, that with the aid of stoves and electric light, fruit, excelling both in sweetness and aroma, and flowers of great brightness, may be grown without solar aid. Dr. Schuibeler mentions that in removing an acacia plant from the dark, and flacing it under the influence of the Arctic midnight sun, the leaves opened slowly, and it is interesting to observe that the same effect took place when an Acacia Lophantha was placed (in the open air) under the influence of my midnight lamp.

\section{PREHISTORIC ANTIQUITIES OF THE AUSTRIAN EMPIRE}

I. CAVES.-The cave of Vypustek, near Brün, in Moravia, was systematically explored, from A pril to end of October 1879 , under the superintendence of the Committee, appointed by the Imperial Academy of Sciences at Vienna, for Prehistoric Investigations. The ossiferous layer, four to five metres thick, and covered with a thin stalagmite, is a non-stratified breccia of sand, loam, pebbles, and angular stones, with bones of "diluvial " mammals abundantly, but irregularly, dispersed. Most of the bones are fragmentary; many of the pieces are rolled, and even polished, by friction. Bones of Ursus spelaus predominate. Eight to ten per cent. belong to thirty other mammalian species. Some bones have evidently been gnawed by porcupines. In a side cave, layers of charcoal and ashes, with fragments of rudely-worked stone implements and bones of domestic animals, showed it to have been once resorted to by human beings.

The Kreuzberg Cave in Carniola has further enriched the Academy's museum with numerous remains of Ursus spelaus. Skeletons of individuals of all ages lie together, but only in the uppermost loam in the highest part of the cave. Thus the animals inhabiting the cave may be supposed to have retired before an irruption of water, and have perished by a flood in in their place of retreat. In a side cave the stalagmitic floor near the entrance contains some charred corn.

A cave near Fiume, on the Adriatic coast, opened by railway. works, appears to have been used as a burial-place in the stone period, as human skeletons, bones of animals, stone implements, and fragments of rude earthenware, were discovered in it.

2. Tumuli.-A tumulus opened in Lower Austria was found to contain only a few worked stones, layers of charcoal, and bones of animals. The skeleton of a woman, executed and buried about seventy years ago, lay in its uppermost portion. In the same province several low barrows were found to contain stones placed in a circle, in the middle of which, on a stone slab, lay the skeleton (not burnt), with many bronze weapon and ornaments. Some larger barrows, probably of later date, are reported to have contained urns and charred bones, a few objects of bronze and iron, and coins of Domitian.

Of more than a hundred tumuli near St. Margareth, Lower Carniola, twenty have been opened. A great many antiquities were obtained: earthen vases of peculiar shape, articles in bronze, iron, glass, and amber, and even gold ornaments.

The tumuli near Jagnenza were found to contain skeletors within elliptical rows of stones, and those near Unter-Erkerstein had urns with burnt haman bones. Another large barrow con tained a circle of stones, a human skeleton, burnt bones, char coal, iron objects, and bronze ornaments.

\section{NOTES FROM ITALY AND SICILY}

THE following notes, although necessarily of a desultory character, may interest some of our readers :-

Climate.-The climate of Southern Europe during the last month, from the middle of December to January 20 , has been more severe than we ever remember it before. Long icicles depended from the platform of the engine which conveyed us

${ }^{x}$ Report of the Committee, \&c., Imperial Academy of Vienna. Repirt of Meeting, December 18, r879. 